\title{
Detection of anthropogenic mortality in elephant Loxodonta africana populations: a long-term case study from the Sebungwe region of Zimbabwe
}

\author{
Kevin M. Dunham
}

\begin{abstract}
A survey of the Sebungwe elephant Loxodonta africana population in Zimbabwe in 2006 revealed a large rise in the number of dead elephants. The estimated number of carcasses increased $>16$-fold from 1989 to 2006 and the carcass ratio (number of all elephant carcasses as a percentage of the number of all elephants) rose from 1.25 to $15.4 \%$. The ratio for fresh or recent carcasses, which reflected the mortality rate during the survey year, increased from 0.19 to $1.70 \%$ during 1995-2006. Records of elephants killed before 1995 were supplemented with estimates of the numbers killed after 1995, with these estimates increasing exponentially, as did the observed number of fresh or recent carcasses. A maximum likelihood analysis to compare population models revealed that the best fit to the survey estimates of this closed population was a model that started with 9,500 elephants in 1979 and that each year increased at $4.02 \%$ and decreased by the number killed, with the number killed annually increasing at $23.5 \%$ per year after 1995. A rise in anthropogenic mortality, mostly due to
\end{abstract}

poaching, caused the increase in carcass numbers observed after 1999. Since 1997 the mortality rate of elephants in the National Parks and Safari Areas in the Sebungwe has been positively correlated with the observed number of poachers' camps. Anthropogenic mortality is now great enough to keep the elephant population approximately constant at 14,000-16,000 animals. The population number was also constant (at a lower level) during the 1980s, when elephants were culled and the sale of meat, hides and ivory covered the costs of elephant management but there have been no recent culls, partly because the ivory trade ban prevents tusks from culled elephants being sold to offset the costs of management. This study illustrates the value of a long-term data set collected with consistent techniques, and including data on other species and the environment collected at no extra cost under the financial umbrella of a charismatic species.

Keywords Aerial survey, carcass, elephant, Loxodonta africana, MIKE, poaching, population model, Zimbabwe.

\section{Introduction}

The African elephant Loxodonta africana is categorized as Vulnerable on the IUCN Red List (IUCN, 2007) and international trade in ivory is banned except for occasional sales by the management authorities of some southern African countries. However, the ban and the sales are controversial (Reeve et al., 2003), with some range states supporting the resumption of the ivory trade as a means to provide funds for conservation and to protect woodlands. Although ivory sales by Namibia, Botswana and South Africa were approved in principle by CITES in 2002, these sales are conditional on the ability of the Monitoring of Illegal Killing of Elephants (MIKE) programme (CITES, 2004) to establish up-to-date and comprehensive data on elephant poaching and populations.

Kevin M. Dunham PO Box CH385, Chisipite, Harare, Zimbabwe. E-mail faykevin@zol.co.zw

Received 12 March 2007. Revision requested 15 May 2007. Accepted 25 June 2007.
The 2006 survey of the closed population of elephants in the Sebungwe region of Zimbabwe, a mosaic of national parks, safari areas and communal lands, revealed that since 2001 there had been a large increase in the number of elephant carcasses, but no decrease in the number of live elephants. The Sebungwe survey programme commenced in 1979 but despite the considerable effort that has gone into it, the population trend has been unclear, being described as stable but with the possibility of a slight increase (Price Waterhouse, 1996; Cumming \& Lynam, 1997), or as stable or declining (Hoare, 1998). Prior to 1980 the number of elephants in the Sebungwe increased at c. 5\% annually (Cumming, 1981) and, since the last cull in 1992, mortality was thought to be low (Hoare, 2000). Hence, if the population growth rate was still $5 \%$ the Sebungwe elephants should have almost doubled in number since 1992.

This study of the long-term trends in the Sebungwe elephant population was undertaken to address two questions: (1) Why was there a large increase in the number of elephant carcasses between 2001 and 2006 
but no decrease in the number of live elephants? (2) What is the current trend of the Sebungwe elephant population and, if the population growth rate is not c. $5 \%$ as it was before 1980 , why has it changed?

A simple population model was used to mimic the observed trends in the Sebungwe elephant population, and then the mortality rate in the modelled population was compared with the observed trend in the number of elephant carcasses. The relevance of this study goes beyond both Sebungwe and its elephant population, and relates to the credibility of sample surveys for monitoring long-term trends in the numbers of savannah elephants and other large herbivores in Africa and beyond. The international attention attracted by elephant poaching during the 1970s (Cumming et al., 1990) and the 1989 ivory trade ban has caused the African elephant to be probably the best monitored of the world's widely-distributed large mammals (Blanc et al., 2004). Sample surveys are often used to census elephants and are a recommended technique for the MIKE programme (Craig, undated).

\section{Study area}

The Sebungwe study area covers $c .15,000 \mathrm{~km}^{2}$ in northwest Zimbabwe, with the southern shore of the manmade Lake Kariba as its northern boundary (Fig. 1). The

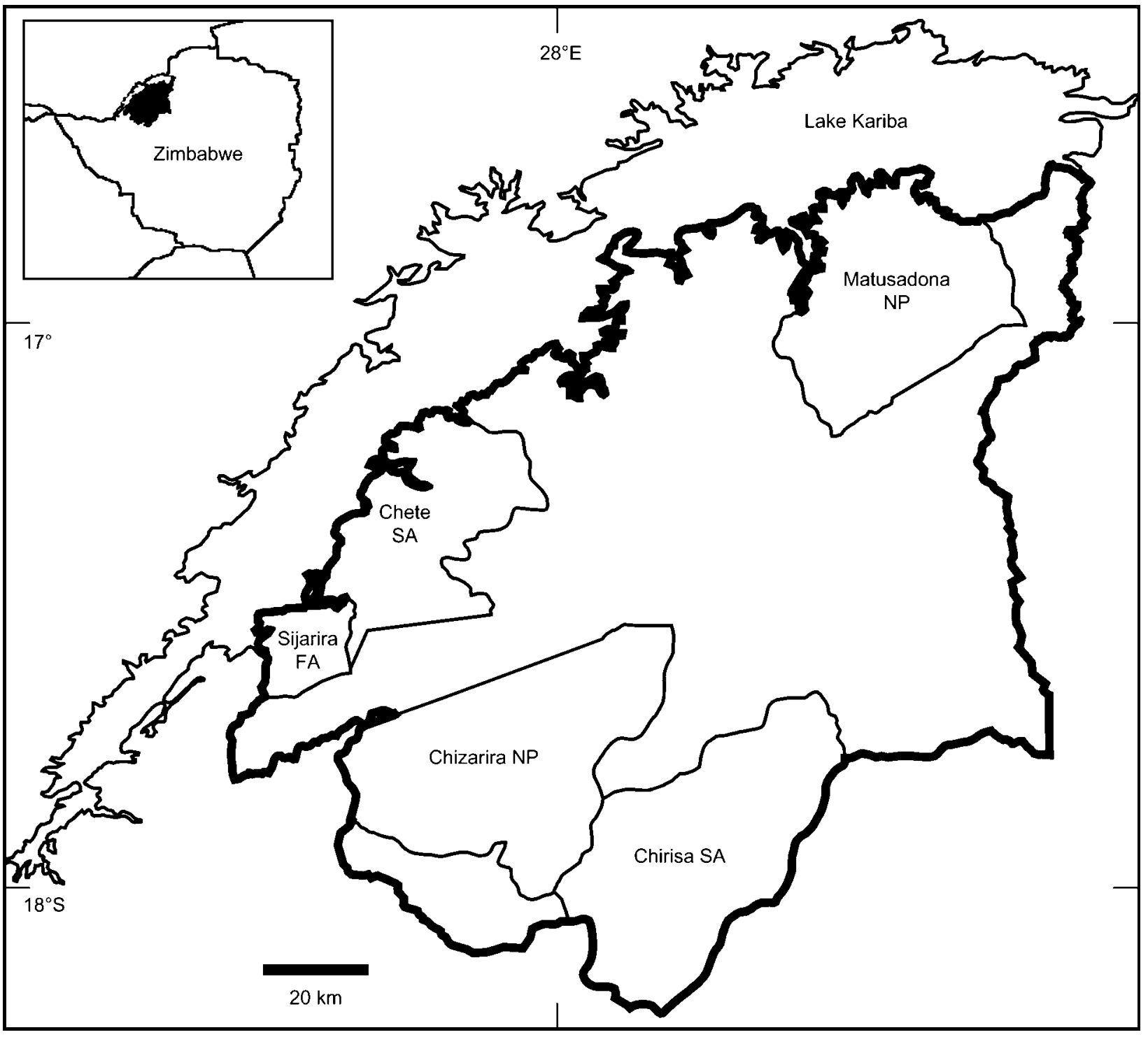

Fig. 1 The Sebungwe region (the insert shows its location in north-west Zimbabwe). The region includes two National Parks (NP), two Safari Areas (SA) and a Forest Area (FA). The remainder of the region is communal land. To the south and the east the boundary of the study area (bold solid line) is the line of the old northern Sebungwe game fence. 
topography varies from almost flat in the unflooded sections of the Zambezi Valley, through undulating hills, to steep escarpments. Mostly-seasonal rivers flow generally north-westwards into Lake Kariba. The natural vegetation is mostly Brachystegia and Julbernardia woodland on higher ground with shallow, light-textured soils, and Colophospermum mopane woodland on heavier soils on valley floors, with riparian woodland along rivers and streamlines, and small areas of thickets and grasslands (Timberlake et al., 1993). Generally, the region experiences a hot wet season during November-April, a cool dry season during May-July and a hot dry season during August-October. Annual rainfall at the Sengwa Wildlife Research Institute in the south of the area averaged $668 \mathrm{~mm}$ (range 288-1,026 mm) during 19651996 (Osborn, 1998). Even at the end of the dry season few parts of the Sebungwe are $>10 \mathrm{~km}$ from drinking water for elephants (Cumming, 1981).

The Sebungwe contains a mosaic of protected areas (Chizarira National Park, 1,910 km²; Matusadona National Park, 1,407 km²; Chirisa Safari Area, 1,713 km² Chete Safari Area, $1,081 \mathrm{~km}^{2}$; collectively known as Parks and Wildlife estate), Sijarira Forest Area (c. $\left.270 \mathrm{~km}^{2}\right)$ and communal lands. Cumming (1981) described the history of land use before 1980, noting how the region's elephants became isolated from other populations by the flooding of the Zambezi Valley following completion of Kariba Dam in 1958, and by a tsetse fly (Glossina spp.) control programme that involved the erection during 1956-1969 of game fences to the south and east of the study area and the shooting of $>2,600$ elephants outside the southern boundary of the study area. Later, many people moved into the area and now people and domestic livestock occupy much of the communal land, and large areas of woodland have been cleared for subsistence and small-scale commercial agriculture (Cumming \& Lynam, 1997). Consequently, the elephant population has been compressed into the Parks and Wildlife estate and those communal areas where the density of people is low (Hoare, 1999; Hoare \& du Toit, 1999). The close proximity of people and elephants prompted the establishment of community-based natural resource management programmes (CAMPFIRE; Martin, 1986). The Sebungwe includes the MIKE study site of Nyami Nyami (CITES, 2004).

Since 1980 elephant management in the Sebungwe has included sport hunting in Chirisa and Chete Safari Areas, in CAMPFIRE areas, and in Sijarira Forest Area, the shooting of problem animals, and the shooting of entire herds (culls) to reduce elephant numbers in the two National Parks and in Chirisa Safari Area during the 1980s and early 1990s. However, the boundaries of the different land-use categories are largely artificial and elephants can and do move freely between the National Parks (where they are legally protected), the Forest and Safari Areas (where small numbers of elephants and other large mammals are hunted annually under licence by sport hunters), and the communal lands (where sport hunting also occurs, and where people, cultivation and domestic livestock are present but at variable densities; Hoare \& du Toit, 1999).

\section{Methods}

\section{Elephant surveys}

The first rigorous census of the Sebungwe elephants was in 1979 (Cumming, 1981). Since then, similar sample aerial surveys have been undertaken regularly during the dry season by the Parks and Wild Life Management Authority (formerly the Department of National Parks \& Wild Life Management), often in partnership with the WWF Southern African Regional Programme Office (references in Table 1). The methods were those recommended for surveys of large African herbivores (Jolly, 1969; Norton-Griffiths, 1978). Dunham et al. (2006) detail the methods. Observers searched for elephants and elephant carcasses but other large herbivores, wild and domestic, and items of interest, e.g. poachers' camps, were also counted. Attempts were made to ensure that observer bias was minimized, and approximately constant between years, by employing keen, experienced, volunteer observers of proven ability and immune to airsickness, and ensuring that search intensity and the widths of search strips were approximately constant between years. Early during the survey programme strata boundaries varied between years, as more information about elephant distribution became available. But since a 1996 review of elephant censusing in Zimbabwe (Price Waterhouse, 1996), techniques have been standardized, thereby facilitating between-year comparisons. The scale of each survey is illustrated by the 2006 census, which involved 72.6 hours of flying, and searching $15 \%$ of the $15,622 \mathrm{~km}^{2}$ survey area (divided into 26 strata, with 24 strata sampled with systematically-arranged transects and two with blocks; Dunham et al., 2006).

\section{Data sources}

Surveys were conducted in 20 years during 1980-2006 and I extracted data on elephants and carcasses from the published reports, and from Price Waterhouse's (1996) summary (Table 1). The number of domestic cattle in the Parks and Wildlife estate provides one index of illegal activities. Since 1997 the reports have included the estimated number of poachers' camps and this estimate provides a second index.

The number of elephants recorded killed by people each year in the Sebungwe for whatever reason, legal or illegal, is given by Martin (1992a) for 1960-1991 and by 
Table 1 Summary of the sample aerial surveys of elephants in the Sebungwe region of Zimbabwe during 1980-2006. There were no surveys in 1986, 1990, 2000 or 2002-2005.

\begin{tabular}{|c|c|c|c|c|}
\hline Year & Size of survey area $\left(\mathrm{km}^{2}\right)$ & Estimated number of elephants & Variance of estimate & Source \\
\hline 1980 & 14,107 & 11,144 & $1,308,204$ & Cumming \& Taylor (1997) \\
\hline 1981 & 12,865 & 8,797 & 712,609 & Cumming \& Taylor (1997) \\
\hline 1982 & 5,715 & 6,111 & * & Price Waterhouse (1996) \\
\hline 1983 & 14,871 & 9,302 & 683,557 & Cumming \& Taylor (1997) \\
\hline 1984 & 6,027 & 5,958 & $*$ & Price Waterhouse (1996) \\
\hline 1985 & 6,038 & 5,150 & * & Price Waterhouse (1996) \\
\hline 1987 & 6,069 & 3,208 & * & Price Waterhouse (1996) \\
\hline 1988 & $13,708^{1}$ & 7,065 & 866,761 & Gibson (1988) \\
\hline 1989 & 12,567 & 13,290 & $3,429,431$ & Gibson (1989) \\
\hline 1991 & 15,118 & 13,533 & $1,996,936$ & Taylor et al. (1992) \\
\hline 1992 & 8,536 & 9,254 & $1,244,376$ & Taylor \& Mackie (1993) \\
\hline 1993 & 15,862 & 10,836 & $1,253,468$ & Cumming et al. (1997) \\
\hline 1994 & $10,733^{2}$ & 8,596 & 632,651 & Mackie (1994) \\
\hline 1995 & 15,685 & 11,797 & 994,141 & Mackie $(1995)^{3}$ \\
\hline 1996 & 15,403 & 13,257 & 900,886 & Mackie (1997) \\
\hline 1997 & 15,597 & 13,388 & 419,501 & Mackie (1998) \\
\hline 1998 & 15,577 & 10,144 & 360,146 & Mackie (1999) \\
\hline 1999 & 15,620 & 16,022 & $1,525,235$ & Dunham (1999) \\
\hline 2001 & 15,622 & 13,988 & $1,146,213$ & Mackie (2002) \\
\hline 2006 & 15,622 & 15,024 & $1,164,503$ & Dunham et al. (2006) \\
\hline
\end{tabular}

*Not given

${ }^{1}$ Highlands of Matusadona National Park were not surveyed; the peak population estimate for this $1,010 \mathrm{~km}^{2}$ stratum was 1,628 elephants during 1997.

${ }^{2}$ Matusadona National Park was not surveyed

${ }^{3}$ With corrections to the carcass estimate

Booth et al. (1996) for 1960-1995. The number killed annually was usually <100, except during 1980-1981, 1984-1986 and 1991-1992 when >2,000 elephants in total were culled. Martin's (1992a) numbers of those killed during 1989-1991 are greater than Booth et al.'s (1996) and I have used the greater numbers because other sources (Payne, 1998) suggest these are more likely to be correct.

\section{Data evaluation}

Prior to 1996 the area of the Sebungwe elephant range that was surveyed varied greatly from year to year (Table 1). Parts of the Parks and Wildlife estate (which contains 65$70 \%$ of the region's elephants; Martin \& Taylor, 1983) were not surveyed during some years. Hence, my analysis included only post-1979 surveys that (1) sampled all of Matusadona and Chizarira National Parks, and Chirisa and Chete Safari Areas, and (2) surveyed a total area $>12,500 \mathrm{~km}^{2}$, i.e. $>80 \%$ of the Sebungwe elephant range. Surveys during 13 years met these conditions.

Preliminary inspection of the elephant data revealed that the annual rate of population growth between consecutive surveys varied from $-24 \%$ during 1997-1998 to $+58 \%$ during $1998-1999$. The latter rate is not credible for a closed population of elephants, and further inspection revealed that of seven large herbivores with populations of $>1,000$ during 1997, six (elephant, buffalo
Syncerus caffer, sable Hippotragus niger, kudu Tragelaphus strepsiceros, waterbuck Kobus ellipsiprymnus and zebra Equus burchelli) supposedly experienced a decline of $>21 \%$ between 1997 and 1998, and then an increase of $>58 \%$ between 1998 and 1999. Increases of this size are not biologically possible in closed populations of these species and the most likely explanation for these observations is that there was marked under-counting bias during the 1998 survey, which I eliminated from the data set. Twelve surveys remained in this set and the annual rate of population increase between consecutive surveys varied from -21 to $+12 \%$.

\section{Elephant carcasses}

The time since death was recorded approximately for each elephant carcass by the observers, who allocated each carcass to an age category (Douglas-Hamilton \& Hillman, 1981), with category 1 representing fresh carcasses, category 2 recent carcasses, and category 3 old carcasses. Generally, category 1 and 2 carcasses were elephants that died during the year of the survey (mostly since the end of the rainy season) and category 3 carcasses were elephants that died either during earlier years, or possibly during the previous rainy season. Carcasses at cull sites were not recorded as carcasses during surveys (Gibson, 1989). 
The survey reports usually gave the carcass ratio sensu Douglas-Hamilton \& Burrill (1991; although it is a percentage, not a ratio), which is the estimated number of all elephant carcasses as a percentage of the estimated number of all elephants (i.e. live plus dead). This allcarcass ratio is an index of the elephant mortality rate (excluding mortality due to culls) during the several years prior to the survey. If the reports included data on carcass categories, I calculated the category $1+2$ carcass ratio, which is an index of the elephant mortality rate during the year of the survey (excluding deaths due to culls but including all other causes, natural and anthropogenic). The category $1+2$ carcass ratio is defined as the estimated number of elephant carcasses in age category 1 or 2, expressed as a percentage of the sum of this number and the estimated number of live elephants. I calculated the 1+2 carcass ratio for the entire Sebungwe, and separate ratios for the Parks and Wildlife estate and the communal lands.

\section{Population trend analysis}

The observed trend in the elephant population was determined by regressing the natural logarithms of the population estimates against time (Caughley, 1977). The slope of this line is the exponential rate of population increase per annum $(r)$ but here population growth rates are presented as percentages $\left(=100\left(\mathrm{e}^{r}-1\right)\right)$, which are generally easier to understand. Statistical analyses were conducted using SYSTAT (Wilkinson, 1997). Regression analysis was also used to determine trends in carcass numbers and ratios. Trends were regarded as statistically significant if the slope of a regression line was significantly different from zero. Two population estimates were regarded as significantly different if their $95 \%$ confidence intervals did not overlap.

\section{Population model}

The number of elephants in the Sebungwe was mimicked with a model that started with an assumed population number, and determined elephant number during the following year by increasing the starting population by an assumed population growth rate, and then reducing it by the number killed during that year (Martin, 1992b). Thus $N_{t}=\left[(1+r / 100) . N_{t-1}\right]-C_{t}$, where $N_{t}=$ number of elephants in year $t, C_{t}=$ number of elephants killed during year $t$, and $r=$ mean rate of population increase per year, as a percentage (where $(1+r / 100)=\lambda$, the growth multiplier (Caughley, 1977)).

The trend in the number of elephants predicted by a model was compared to the survey estimates of elephant number using Martin's (1992b) maximum likelihood estimator (Appendix). The outcome of this analysis is an estimator that equals one if the predicted and estimated numbers are identical during all survey years, and declines towards zero the less perfect the fit between the predicted and estimated numbers. For convenience, this estimator is multiplied by 1,000 to give an index value. When several models are compared, the one that gives the greatest index value is the model that provides the best fit to the survey estimates.

I considered the possibility that additional elephants may have been killed before 1995 and that the real number killed may have been greater than the recorded number. During the first phase of the modelling the model was run for 1979-1995 and the Microsoft Excel add-in Solver was used to determine the values of the starting population during 1979, the population growth rate and the number of additional (unrecorded) elephants shot annually during 1980-1995 that maximized the index value. The initial assumed starting population was 10,000 and constrained to be an integer $\geq 8,000$ and $\leq 12,000$, as estimated by a 1979 survey (Cumming, 1981). The initial assumed mean growth rate of the population was $3.5 \%$ annually (and constrained to be $\geq 0$ and $\leq 7 \%$ ). The initial assumed number of additional elephants killed annually was 100 (and constrained to be an integer $\geq 0$ and $\leq 200$ ). Executing Solver was equivalent to running a series of models with different combinations of a starting population, a growth rate and a number of additional elephants killed. There were seven surveys during 1980-95, and to determine the robustness of the conclusions the procedure was repeated seven times, each time dropping a different survey estimate from the calculation of Martin's (1992b) index value.

The first phase of the modelling revealed that the fit of the predicted population numbers to the survey estimates during 1980-1995 was not improved by assuming that unrecorded elephants were killed during this period. Hence, during the second phase I assumed that the numbers killed during 1980-1995 were the recorded numbers. However, there are no published records of the numbers killed during 1996-2006 and I assumed that the number killed annually after 1995 may have increased. The model was run for 1979-2006 and Solver used to determine the values of the starting population during 1979, the population growth rate and the exponential rate of increase in the number of elephants killed annually after 1995 that maximized Martin's index value. The initial assumed exponential rate of increase in the number of elephants killed annually was zero, equivalent to a constant number killed each year after 1995, and the exponential constant was constrained to be $\geq 0$ and $\leq 0.5$. There were 12 surveys during 1980-2006 and to determine the robustness of the conclusions the procedure was repeated 12 times, each time dropping a different survey estimate from the calculation of the index value. 


\section{Results}

\section{Elephants}

The number of elephants in the Sebungwe increased from 9,000-11,000 during the early 1980s to 14,000-16,000 during 1999-2006 (Fig. 2). The mean observed rate of increase during 1980-2006 was 1.85\% annually (equivalent to an exponential rate of 0.0183 per annum).

\section{Carcasses}

The estimated number of all elephant carcasses in the Sebungwe increased $>16$-fold from 1989 to 2006 . Carcass number was approximately constant during 1989-1993, then increased three-fold to a new constant level during 1996-1999 and thereafter increased dramatically to 2,733 during 2006 (Fig. 3a). Similarly, the all-carcass ratio increased from $1.25 \%$ during 1989 to $15.4 \%$ during 2006 (Fig. 3b).

The estimated number of fresh or recent carcasses in the Sebungwe increased from 23 during 1995 to 260 during 2006, with an exponential model providing a good fit to the mean estimates (Fig. 3c). Similarly, the category 1+2 carcass ratio increased from $0.19 \%$ during 1995 to $1.70 \%$ during 2006 (Fig. 3d). The increase in this ratio indicated there was a large rise in the mortality rate: the increase in the number of fresh or recent carcasses was not simply a consequence of a larger number of elephants dying because there were more live elephants. In the communal lands the major increase in the category $1+2$ carcass ratio (and therefore in the mortality rate) was between 1999 and 2001, but in the Parks and Wildlife estate the major rise was between 2001 and 2006 (Fig. 3d).

The estimated number of old carcasses in the Sebungwe increased >5-fold between 1995 and 2006 . There were 1,717 more old carcasses during 2006 than in 2001 and most of these were elephants that died before, not during, 2006. This indicated that the mortality rate was high not only during 2006 but also during the intervening (non-survey) years of 2002-2005.

\section{Population model}

The maximum likelihood analysis to compare population models for 1979-1995 revealed that a model population during 1979 of approximately 9,600 elephants, which each year increased at a rate of $3.77 \%$ and decreased by only the recorded number killed, provided a better fit to the survey estimates during 1980-1995 than alternative models with different starting populations, growth rates, or any additional (unrecorded) elephants killed. Although there were small variations in the starting population and growth rate according to which survey estimates were included in the likelihood analysis, the number of additional elephants killed was consistently zero in the best models (Table 2).

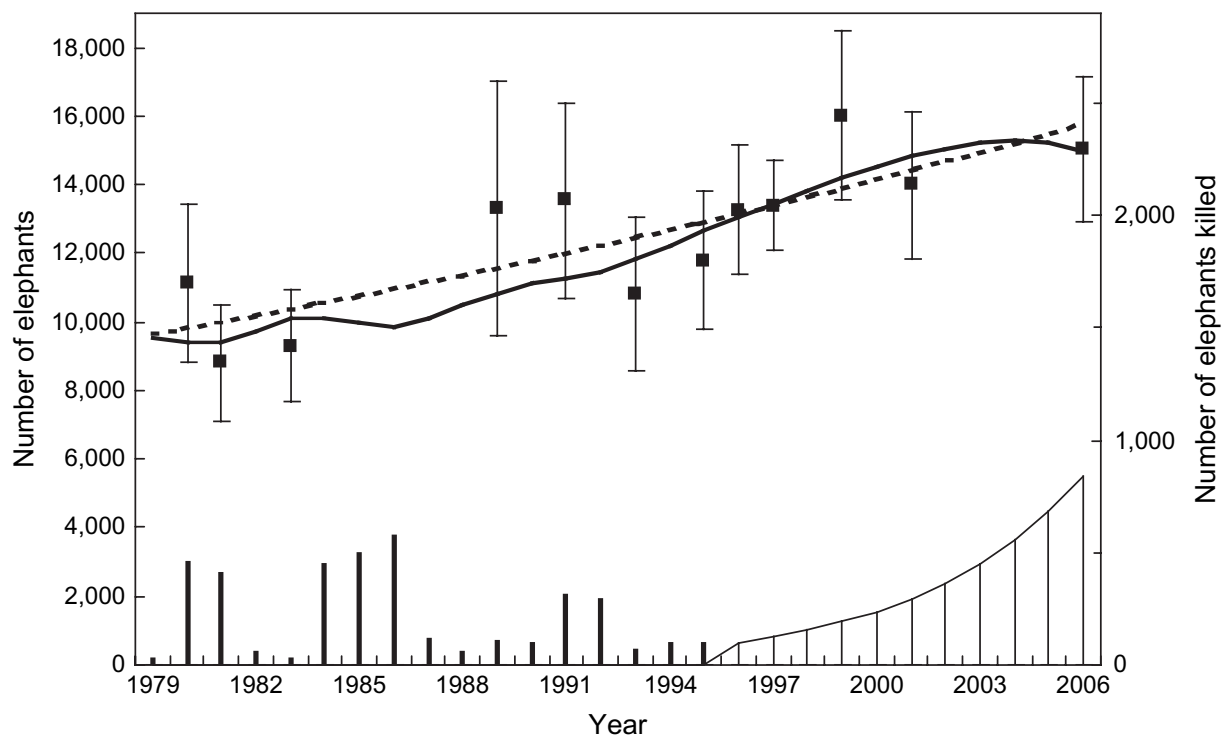

Fig. 2 Number of elephants in the Sebungwe, as estimated by aerial surveys during 1980-2006, with mean population estimates and $95 \%$ confidence intervals (left axis). Data sources as in Table 1. The observed trend (dashed line) is an exponential curve calculated from the slope $(r)$ of a linear regression of the natural logarithm of the mean estimate against year $(r=0.0183 \pm \mathrm{SE} 0.0042, \mathrm{n}=12$, $t=4.341, \mathrm{P}=0.0015)$. The trend (bold line) in a modelled population that gave the best fit to the survey estimates is also shown. The modelled population started with 9,501 elephants during 1979, grew at 4.02\% per annum and each year was reduced by the number killed that year (histogram, right axis: for 1980-1995, number recorded killed; for 1996-2006, estimated number killed, with the estimated number killed increasing at $23.5 \%$ per annum). Note differing scales for left and right axes. 

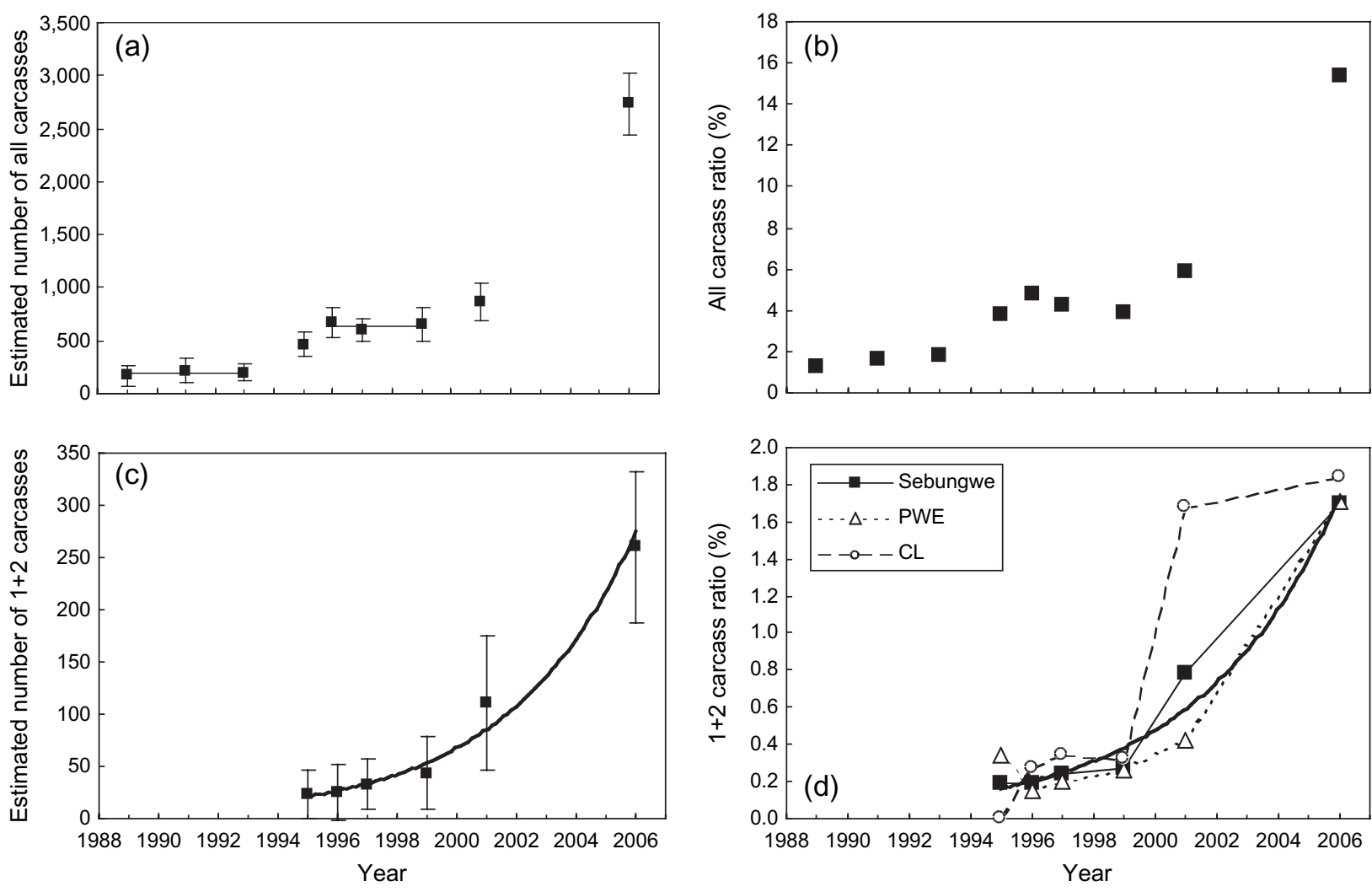

Fig. 3 (a) The number of all carcasses of elephants in the Sebungwe, as estimated by aerial surveys, with mean estimates and $95 \%$ confidence intervals. This estimate is an index of the number of elephants that died during the several (but unknown number of) years prior to the survey. The horizontal lines indicate the mean values for 1989-1993 (196) and 1996-1999 (641). Data sources as in Table 1. Carcass data were not reported for pre-1989 surveys. (b) The all-carcass ratio for elephants in the Sebungwe during 1989-2006. This ratio provides an index of the mortality rate of elephants during the several (but unknown number of) years prior to the survey. (c) The number of fresh or recent carcasses (category 1 or 2) of elephants in the Sebungwe, as estimated by aerial surveys, with mean estimates and confidence intervals. This estimate is an index of the number of elephants that died during the survey year. Carcass age categories have been reported for all surveys since 1995. The observed trend (bold line) is an exponential curve calculated from the slope $(r)$ of a linear regression of the natural logarithm of the mean estimate against year $(r=0.2336 \pm \mathrm{SE} 0.0200,95 \%$ confidence limits $=0.18 \& 0.29, \mathrm{n}=6, t=11.658, \mathrm{P}=$ $\left.0.0003, r_{\text {adj }}^{2}=0.97\right)$. (d) The category $1+2$ carcass ratio for elephants in the Sebungwe during 1995-2006. This ratio provides an index of the mortality rate of elephants during the survey year. Ratios are shown separately for the entire Sebungwe study area, for the Parks and Wildlife estate (PWE) and for the communal lands (CL).

The maximum likelihood analysis to compare population models for 1979-2006 revealed that the best fit to the survey estimates during 1980-2006 was a model that started with a population of $c .9,500$ elephants during 1979 and that each year increased at a rate of $4.02 \%$ and decreased by the number of elephants recorded killed during 1980-1995 and estimated killed during 1996-2006, with this estimated number increasing by $23.5 \%$ annually (equivalent to an exponential rate of 0.211 per year; Fig. 2, Table 3). The fit of this model was better than that of alternative models with different starting populations, growth rates, or rates of increase in the number of elephants killed annually after 1995. If the 2006 survey estimate was not included in the likelihood analysis, the predicted population trend after 2001 was a poor fit to the observed trend because the increase in the number of elephants killed annually after 1995 was overestimated.

The rate of increase in the number of elephants killed annually after 1995 (23.5\%) in the best-fitting population model was within the confidence limits of the annual rate of increase in the number of fresh and recent carcasses observed during surveys (26.3\%; Fig. 3c). This same model predicted that 2,894 elephants were killed between the 2001 and 2006 surveys.

\section{Illegal activities}

Illegal activities in the Parks and Wildlife estate, as indicated by the numbers of poachers' camps and cattle, 
Table 2 Parameters for elephant population models for 1979-1995 that assumed that the number killed annually during 1980-1995 may have been greater than the number recorded killed. A series of models was run using different combinations of an assumed starting population, an assumed growth rate, and an assumed number of additional (unrecorded) elephants killed. This table gives the parameters for the model that provided the best fit of the predicted population numbers to the estimated numbers. Index values were calculated first using all survey estimates and then recalculated seven times, each time dropping one estimate from the calculation. The mean values are for models selected using index values calculated with only six survey estimates.

\begin{tabular}{lllll}
$\begin{array}{l}\text { Survey year } \\
\text { dropped from } \\
\text { index value } \\
\text { calculation }\end{array}$ & $\begin{array}{l}\text { Peak } \\
\text { index value }\end{array}$ & $\begin{array}{l}\text { Starting population } \\
\text { number during 1979 }\end{array}$ & $\begin{array}{l}\text { Population mean } \\
\text { growth rate (\% per yr) }\end{array}$ & $\begin{array}{l}\text { Number of additional } \\
\text { elephants killed annually } \\
\text { during 1980-1995 }\end{array}$ \\
\hline none & $*$ & 9,603 & 3.77 & 0 \\
1980 & 34.7 & 9,066 & 4.30 & 0 \\
1981 & 15.7 & 10,105 & 3.33 & 0 \\
1983 & 19.4 & 10,089 & 3.39 & 0 \\
1989 & 26.5 & 9,517 & 3.76 & 0 \\
1991 & 50.5 & 9,552 & 3.60 & 0 \\
1993 & 12.4 & 9,574 & 3.96 & 0 \\
1995 & 12.1 & 9,464 & 4.17 & 0 \\
Mean & & 9,624 & 3.78 & 0 \\
\hline
\end{tabular}

*Not given because this index value was calculated as the product of seven relative values and so cannot be compared with the other index values in this table, which were calculated as the product of six relative values.

increased between 2001 and 2006 (Fig. 4a). The elephant mortality rate in the Parks and Wildlife estate during any survey year (as indexed by the category $1+2$ carcass ratio) was significantly and positively correlated with the number of poachers' camps in the estate during the same year (Fig. 4b).

\section{Discussion}

\section{Trends in the Sebungwe elephant population}

The trend of the modelled population that gave the best fit to the survey estimates (Fig. 2) is likely to be a reasonable representation of the trend exhibited by the

Table 3 Parameters for elephant population models for 1979-2006 that assumed that the number of elephants killed annually after 1995 may have increased exponentially. A series of models was run using different combinations of an assumed starting population, an assumed growth rate and an assumed rate of increase in the number of elephants killed annually after 1995. This table gives the parameters for the model that provided the best fit of the predicted population numbers to the estimated numbers. Index values were calculated first using all survey estimates and then recalculated 12 times, each time dropping one estimate from the calculation. When the 2006 estimate was dropped the predicted population trend line did not pass through the confidence interval of the 2006 survey estimate. The mean values are for the models selected using the reduced data sets for the analysis, but excluding the model selected when the 2006 estimate was dropped.

\begin{tabular}{|c|c|c|c|c|}
\hline $\begin{array}{l}\text { Survey year } \\
\text { dropped from } \\
\text { index value } \\
\text { calculation }\end{array}$ & $\begin{array}{l}\text { Peak } \\
\text { index value }\end{array}$ & $\begin{array}{l}\text { Starting population } \\
\text { number during } 1979\end{array}$ & $\begin{array}{l}\text { Population mean } \\
\text { growth rate (\% per yr) }\end{array}$ & $\begin{array}{l}\text { Rate of increase in } \\
\text { number of elephants } \\
\text { killed annually after } \\
1995 \text { (\% per yr) }\end{array}$ \\
\hline none & * & 9,501 & 4.02 & 23.5 \\
\hline 1980 & 8.02 & 9,049 & 4.38 & 25.6 \\
\hline 1981 & 2.98 & 9,870 & 3.74 & 21.7 \\
\hline 1983 & 3.98 & 9,934 & 3.70 & 21.6 \\
\hline 1989 & 5.00 & 9,380 & 4.10 & 23.7 \\
\hline 1991 & 7.39 & 9,355 & 4.10 & 23.4 \\
\hline 1993 & 3.08 & 9,572 & 4.00 & 23.9 \\
\hline 1995 & 2.97 & 9,531 & 4.04 & 24.3 \\
\hline 1996 & 2.02 & 9,500 & 4.01 & 23.2 \\
\hline 1997 & 1.98 & 9,496 & 4.04 & 23.8 \\
\hline 1999 & 6.86 & 9,601 & 3.86 & 21.3 \\
\hline 2001 & 2.91 & 9,394 & 4.16 & 24.7 \\
\hline 2006 & 2.19 & 9,421 & 4.14 & 38.0 \\
\hline Mean (excluding when 2006 dropped) & & 9,517 & 4.01 & 23.4 \\
\hline
\end{tabular}

*Not given because this index value was calculated as the product of 12 relative values and so cannot be compared with the other index values in this table, which were calculated as the product of 11 relative values. 

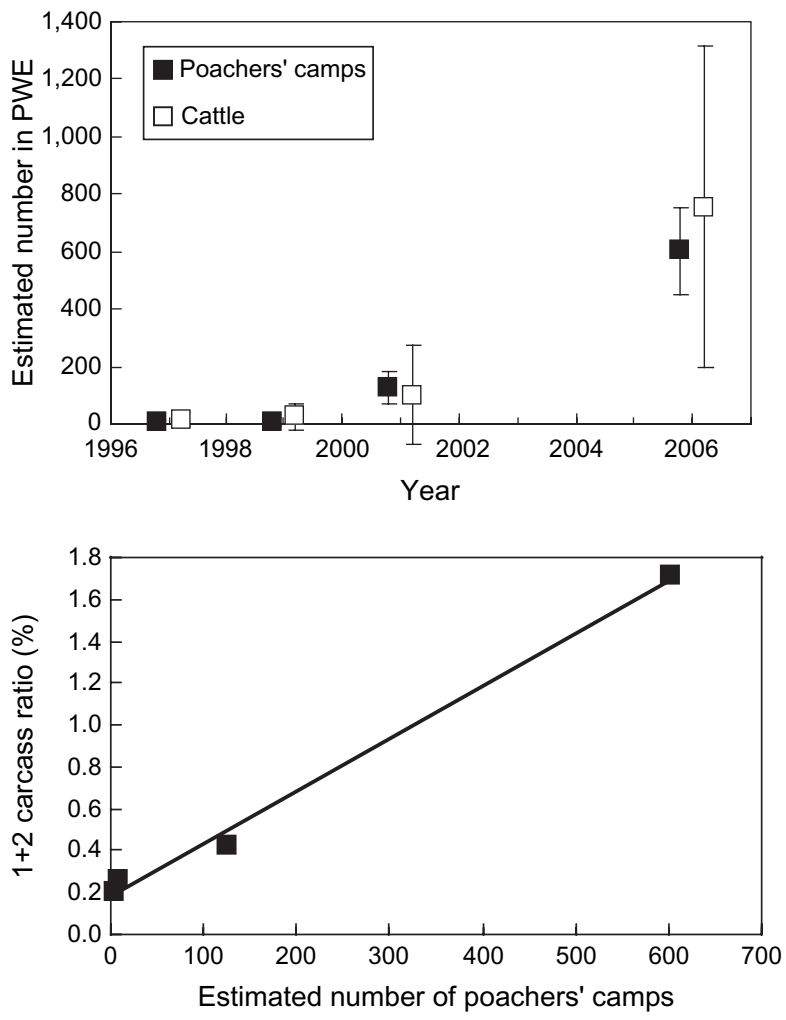

Fig. 4 (a) The numbers of poachers' camps and cattle (indices of illegal activity) in the Parks and Wildlife estate (PWE) of the Sebungwe, as estimated by aerial surveys, with mean estimates and $95 \%$ confidence intervals. Data sources as in Table 1. Poachers'camps were not reported for pre-1997 surveys. (b) The mortality rate of elephants in the Sebungwe Parks and Wildlife estate, as indexed by the category $1+2$ carcass ratio for the estate, was correlated with the estimated number of poachers'camps in the estate ( $\mathrm{n}=4$ surveys; 1997, 1999, 2001 and 2006, correlation coefficient $=0.9968, \mathrm{P}<0.01$; line for illustrative purposes).

Sebungwe elephant population since 1980. When anthropogenic mortality was discounted this population increased at $4.02 \%$ annually. This mean rate represented the excess of births over natural deaths. It is close to the $5 \%$ rate displayed before 1980 (Cumming, 1981) and similar to two predictions (4.32 and $4.89 \%$ ) based largely on data from elephants culled in the Sebungwe (Craig, 1989).

The simple population model used here assumed that the difference between the fecundity and mortality rates was approximately constant from year to year, although for elephants this is not always so (Gough \& Kerley, 2006). The model's predicted population trend would always be a poor fit to survey estimates if there is unusually high natural mortality in any year. An apparent decline in the number of elephants in the Sebungwe between 1991 and 1993 coincided with a severe drought across southern Africa and some elephant populations, e.g. in Gonarezhou, suffered significant mortality (Leggett, 1994). However, the Sebungwe population appeared to be relatively unaffected, with no obvious increase in mortality (S. Alibhai \& Z. Jewell, pers. comm.; K. Payne, pers. comm.). In the Sebungwe it was during 1994-1995 that rainfall was particularly low and while there was no evidence that the number of live elephants declined then, the all-carcass ratio doubled between 1993 and 1995. But $95 \%$ of carcasses seen during the 1995 survey were of elephants that died before the 1995 dry season. Hence, the Sebungwe elephants appeared to be less susceptible to drought-related mortality than some other elephant populations.

There were three phases in the trend of the Sebungwe elephant population during 1980-2006. During 19801987 population number was approximately constant, with the culling of $>2,000$ elephants preventing any increase. After 1987, until c. 1999, the population number increased steadily because anthropogenic mortality was generally low (the numbers of elephants culled during 1991 and 1992 were too small to prevent the increase). After 1999 the mortality rate rose sharply and was high enough during the early 2000s to check any further increase in elephant number. There is close agreement between the observed rate of increase after 1995 in the number of fresh or recent carcasses, and the rate of increase in the number of elephants killed annually after 1995 that must be included in a model that mimics the most recent trend in the elephant population.

To keep elephant numbers in the Sebungwe approximately constant at 15,000 (mean of the 1999, 2001 and 2006 estimates) would require 600 elephants to be killed annually, assuming a population growth rate of $4 \%$. These 600 deaths are in addition to natural deaths. For comparison, the observed increase in the number of elephant carcasses between the 2001 and 2006 surveys averaged 373 per year but this figure, which includes natural deaths, makes no allowance for carcasses that decayed or otherwise disappeared.

Elephants have been killed in the Sebungwe for various reasons, including culls, tsetse control, sport hunting, Parks and Wild Life Management Authority staff training and rations, problem animal control, crop protection and illegal hunting (Martin, 1992a). There have been no culls since 1992 and tsetse control operations no longer use game fences or game-free corridors. Sport hunting is unlikely to account for the increased mortality of elephants after 1999 because the number of elephants that sport hunters were licensed to kill annually was constant at 60-70 during 1994-2002 (Grobbelaar \& Masulani, 2003). Ivory records account for an average of $<100$ elephants per year that died in the communal lands between the 2001 and 2006 surveys (O. Ndoro, pers. comm.) and this number includes elephants killed during problem animal control and sport hunting, and 
some natural deaths. There are no published data on the numbers shot by Parks and Wild Life Management Authority staff for rations, or staff training. Despite gaps in the data, it is most unlikely that the increase in elephant mortality since 1999 can be accounted for by the legal killing of elephants.

The significant and positive correlation between the elephant mortality rate in the Parks and Wildlife estate and the number of poachers' camps there strongly implies that, at least within the estate, the increase in elephant mortality was due to poaching. A simultaneous increase in the number of domestic cattle illegally in the estate, and the recent presence of cattle-drawn carts (Dunham et al., 2006), suggests that the problem was not just elephant poaching but a wider problem of a lack of law enforcement. Zimbabwe's capacity to provide effective law enforcement in the Parks and Wildlife estate is constrained by small budgets (Cumming \& Jones, 2005), often compounded by inappropriate allocations of resources (Attwell \& Cotterill, 2000).

That the sharp rises in the mortality rates of elephants in the Parks and Wildlife estate and in the communal lands occurred at different times may suggest different causes. However, the limited records of elephant offtake in the Sebungwe communal lands during 1996-2006 provide no evidence of a major rise in the legal offtake (O. Ndoro, pers. comm.). One could speculate that poaching caused both rises but that extensive poaching started in the communal lands before the 2001 survey and in the Parks and Wildlife estate afterwards.

\section{Conservation implications}

That the number of dead elephants within an area can increase significantly without the number of live ones declining may appear counter-intuitive, and could be dismissed as erroneous, especially if survey techniques are not consistent. In the Sebungwe a population that had been increasing was subjected to additional illegal hunting, hence the extra carcasses, which caused the population number to level off. The value of a long-term data set is further emphasized when additional information is collected during surveys so that temporal and spatial trends in the numbers of elephants and other large herbivores can be related to trends in, for example, human density, woodland clearance and domestic livestock (Cumming \& Lynam, 1997). The elephant enjoys a high international profile and the Sebungwe surveys were often funded specifically to census elephants: additional data, on other species and the environment, were collected at no extra cost under the financial umbrella of the charismatic study species. The methods used here to determine the long-term trend in elephant number can be extended to these other species and any population censused in a consistent manner for a reasonable period.

In future both the all-carcass ratio and the category $1+2$ carcass ratio should be reported for elephant surveys. As an index of the mortality rate the all-carcass ratio can suggest a trend in a population even when survey data are too few or too variable to reveal one (Douglas-Hamilton \& Burrill, 1991). But because the allcarcass ratio represents the mortality rate during an unknown period prior to the survey, it reveals only the recent trend, at least in general terms, not necessarily the current trend. The category $1+2$ carcass ratio, as an index of the mortality rate during the survey year, is more useful in revealing the current trend. This is well illustrated for the Sebungwe: while the all-carcass ratio was $21 \%$ greater during 2001 than during any previous survey, the category $1+2$ carcass ratio was $193 \%$ greater. The category $1+2$ carcass ratio reveals that the rise in the mortality rate of the Sebungwe elephants commenced before 2001, useful information that was inadequately captured by the all-carcass ratio.

Surveys of other elephant populations are needed to determine if the poaching upsurge is confined to the Sebungwe, or a national problem, or a continent-wide problem. Zimbabwe's elephants in north-west Matabeleland and Gonarezhou were last surveyed in 2001 and plans to re-survey them in 2006 were postponed. Zimbabwe's fourth major elephant population, in the unflooded Middle Zambezi Valley, was surveyed during 2005 but the report is still (December 2007) awaited. Media reports that at least some poaching in the Sebungwe is conducted by Zambian nationals suggest that there is an international dimension to the poaching and that it is not simply a local breakdown in law enforcement. That the Sebungwe elephant poaching may be part of a wider problem is also implied by an analysis of the Elephant Trade Information System records of world-wide seizures of illegal ivory, which suggest that the illicit trade in ivory is once again increasing (Milliken et al., 2007). The MIKE programme has yet to report on temporal trends in poaching (CITES, 2004, 2007).

This study provides no support for claims that variations in natural mortality, the inter-calving interval and the age at sexual maturity make significant contributions to the variation in the observed trends in southern African elephant populations (van Aarde \& Jackson, 2007). The Sebungwe contains a matrix of land use types, without artificial waterpoints for wildlife or fences to limit dispersal but despite this the variation in the trend of the elephant population since 1980, and before (Cumming, 1981), appears to be mostly due to fluctuations in the level of anthropogenic mortality. Although the Sebungwe population has now been stabilized by this mortality, the overall mean density of 
elephants in the protected areas is greater than that which is likely to permit the recovery of woodlands that have been converted to shrublands by elephants (Martin et al., 1989). Zimbabwe's elephant policy calls for elephant density in protected areas to be kept below levels that 'compromise biodiversity' (Department of National Parks \& Wild Life Management, undated), in practice $<0.75$ elephants $\mathrm{km}^{-2}$ (D.H.M. Cumming, pers. comm.).

During most of the 1980s elephant number in the Sebungwe was kept approximately constant by culling, with the sale of meat, hides and ivory from culled elephants covering the costs of elephant management. However, there have been no recent culls, partly because the ivory trade ban prevents tusks from culled elephants being sold to offset the costs of management and protection. Although poachers are now limiting the Sebungwe elephant population, the current number $(14,000-16,000)$ is greater than during the 1980s $(9,000-$ $11,000)$. Thus, the advent of the ivory trade ban was followed by an increased density of elephants and presumably by greater impacts on the woody vegetation, already seriously modified by elephants. If there is a continued absence of effective law enforcement, poachers rather than managers may be responsible for reducing elephant density in the Sebungwe to that set by the national policy. It will be ironic if a consequence of the ivory trade ban is more poaching, rather than less.

The credibility of the Sebungwe surveys is confirmed: there is no contradiction between the increase observed during 2006 in the number of dead elephants and the approximately constant population of live elephants. The carcasses represented what would have been an increase in the live population if there had not been additional mortality, mainly due to poaching, after 1999. During the 1990s the number of elephants was increasing but by 2006 the number killed annually was high enough to keep the population number constant.

\section{Acknowledgements}

I thank Rowan Martin, Abel Khumalo, Jon Cadd, Russell Taylor and Onias Ndoro for help in various ways, and Fay Robertson and David Cumming for criticisms of earlier drafts. Many people have contributed to the Sebungwe surveys: I mention especially Ian Coulson, Timothy Chifamba, Andrew Masarirevhu and Jill Adair, all of whom died as a consequence of the crash of the survey plane in 1994.

\section{References}

Attwell, C.A.M. \& Cotterill, F.P.D. (2000) Postmodernism and African conservation science. Biodiversity and Conservation, 9 , 559-577.
Blanc, J.J., Barnes, R.F.W., Craig, G.C., Douglas-Hamilton, I., Dublin, H.T., Hart, J.A. \& Thouless, C.R. (2004) Changes in elephant numbers in major savanna populations in eastern and southern Africa. Pachyderm, 38, 19-28.

Booth, V.R., Martin, R.B., Child, B. \& Chingwendere, L. (1996) The number of elephants killed in Zimbabwe: 1960-1995. In Elephant Management in Zimbabwe, 3rd edition (eds R.B. Martin, G.C. Craig \& V.R. Booth), pp. 45-49. Department of National Parks and Wild Life Management, Harare, Zimbabwe.

Caughley, G. (1977) Analysis of Vertebrate Populations. J. Wiley \& Sons, Chichester, UK.

CITES (2004) Monitoring of Illegal Hunting in Elephant Range States. A Report to the 13th meeting of the Conference of the Parties to CITES. CoP13 Doc. 29.3. CITES Secretariat, Geneva, Switzerland.

CITES (2007) Monitoring of Illegal Hunting in Elephant Range States. A Report to the 14th meeting of the Conference of the Parties to CITES. CoP14 Doc. 53.3. CITES Secretariat, Geneva, Switzerland.

Craig, G.C. (undated) Aerial Survey Standards for the MIKE Programme. CITES MIKE Programme, Nairobi, Kenya.

Craig, G.C. (1989) Population dynamics of elephants. In Elephant Management in Zimbabwe (eds R.B. Martin, G.C. Craig \& V.R. Booth), pp. 67-72. Department of National Parks and Wild Life Management, Harare, Zimbabwe.

Cumming, D.H.M. (1981) The management of elephant and other large mammals in Zimbabwe. In Problems in Management of Locally Abundant Wild Mammals (eds P.A. Jewell, S. Holt \& D. Hart), pp. 91-118. Academic Press, New York, USA.

Cumming, D.H.M., Du Toit, R.F. \& Stuart, S.N. (1990) African Elephants and Rhinos. Status Survey and Conservation Action Plan. IUCN, Gland, Switzerland.

Cumming, D. \& Jones, B. (2005) Elephants in Southern Africa: Management Issues and Options. WWF-SARPO Occasional Paper 11. WWF-SARPO, Harare, Zimbabwe.

Cumming, D.H.M. \& Lynam, T.J.P. (eds) (1997) Land Use Changes, Wildlife Conservation and Utilisation, and the Sustainability of Agro-ecosystems in the Zambezi Valley. Final Technical Report, Volumes 1-7. WWF-SARPO, Harare, Zimbabwe.

Cumming, D.H.M. \& Taylor, R.D. (1997) Aerial census summaries: 1980-1996. In Land Use Changes, Wildlife Conservation and Utilisation, and the Sustainability of Agroecosystems in the Zambezi Valley (eds D.H.M. Cumming \& T.J.P. Lynam), annex 5.1.4. Final Technical Report. WWF-SARPO, Harare, Zimbabwe.

Cumming, D.H.M., Taylor, R.D. \& Mackie, C.S. (1997) Aerial census of wild and domestic larger herbivores in the Sebungwe region of Zimbabwe: September 1993. In Land Use Changes, Wildlife Conservation and Utilisation, and the Sustainability of Agro-ecosystems in the Zambezi Valley (eds D.H.M. Cumming \& T.J.P. Lynam), annex 5.1.2. Final Technical Report. WWF-SARPO, Harare, Zimbabwe.

Department of National Parks and Wild Life Management (undated) [1997?] The Policy and Plan for Elephant Management in Zimbabwe. Department of National Parks and Wild Life Management, Harare, Zimbabwe.

Douglas-Hamilton, I. \& Burrill, A. (1991) Using elephant carcass ratios to determine population trends. In African Wildlife: Research and Management (eds F.I.B. Kayanja \& E.L. Edroma), pp. 98-105. International Council of Scientific Unions, Paris, France.

Douglas-Hamilton, I. \& Hillman, A.K.K. (1981) Elephant carcasses and skeletons as indicators of population trends. In 
Low Level Aerial Survey Techniques. Report of An International Workshop, 6-11 November 1981, Nairobi, pp. 113-129. ILCA Monograph 4. International Livestock Centre for Africa, Addis Ababa, Ethiopia.

Dunham, K.M. (1999) Aerial Census of Elephants and other Large Herbivores in the Sebungwe Region, Zimbabwe: 1999. WWF-SARPO Project Paper 72. WWF-SARPO, Harare, Zimbabwe.

Dunham, K.M., Mackie, C.S., Musemburi, O.C., Chipesi, D.M., Chiweshe, N.C., Taylor, R.D. et al. (2006) Aerial Survey of Elephants and other Large Herbivores in the Sebungwe Region, Zimbabwe: 2006. WWF-SARPO Occasional Paper 12. WWFSARPO, Harare, Zimbabwe.

Gibson, D.St.C. (1988) Aerial Census of Larger Mammals in the Sebungwe Region September/October 1988. Department of National Parks and Wild Life Management, Harare, Zimbabwe.

Gibson, D.St.C. (1989) Aerial Census of Larger Mammals in the National Parks Estate of Zimbabwe August-October 1989. Department of National Parks and Wild Life Management, Harare, Zimbabwe.

Gough, K.F. \& Kerley, G.I.H. (2006) Demography and population dynamics in the elephants Loxodonta africana of Addo Elephant National Park, South Africa: is there evidence of density dependent regulation? Oryx , 40, 434-441.

Grobbelaar, C. \& Masulani, R. (2003) Review of Offtake Quotas, Trophy Quality and 'Catch Effort' Across the Four Main Wildlife Species Elephant, Buffalo, Lion and Leopard. Unpublished Report. WWF-SARPO, Harare, Zimbabwe.

Hoare, R.E. (1998) Human-elephant interactions at the ecosystem level. Pachyderm, 25, 41-42.

Hoare, R.E. (1999) Determinants of human-elephant conflict in a land-use mosaic. Journal of Applied Ecology, 36, 689-700.

Hoare, R.E. (2000) Effects of habitat on visibility of elephants during aerial census. Pachyderm, 29, 25-28.

Hoare, R.E. \& du Toit, J.T. (1999) Coexistence between people and elephants in African savannas. Conservation Biology, 13, 633-639.

IUCN (2007) 2007 IUCN Red List of Threatened Species. IUCN, Gland, Switzerland. Http://www.iucnredlist.org [accessed 12 December 2007].

Jolly, G.M. (1969) Sampling methods for aerial censuses of wildlife populations. East African Agriculture and Forestry Journal, 34, 46-49.

Leggett, K.E.A. (1994) Implications of the Drought on Elephants in Gonarezhou National Park: A Preliminary Report on the Raleigh International Expeditions $93 \mathrm{~K}$ and $94 \mathrm{~B}$ to Gonarezhou National Park, September 1993 to May 1994. Unpublished Report to the Department of National Parks and Wild Life Management, Harare, Zimbabwe.

Mackie, C. (1994) Aerial Census of Elephant and other Large Herbivores in Selected Areas of the Parks and Wildlife Estate and Communal Lands 1994. WWF-SARPO Project Paper 48. WWFSARPO, Harare, Zimbabwe.

Mackie, C. (1995) Aerial Census of Elephant and other Large Herbivores in the Sebungwe, Dande and Zambezi Valley Escarpment 1995. WWF-SARPO Project Paper 49. WWFSARPO, Harare, Zimbabwe.

Mackie, C. (1997) Aerial Census of Elephant and other Large Herbivores in the Sebungwe, Dande, Zambezi Valley Escarpment and Southeast Lowveld Communal Lands 1996. WWF-SARPO Project Paper 50. WWF-SARPO, Harare, Zimbabwe.

Mackie, C. (1998) Aerial Census of Elephants and other Large Herbivores in the Sebungwe and Dande Communal Lands 1997.
WWF-SARPO Project Paper 56. WWF-SARPO, Harare, Zimbabwe.

Mackie, C. (1999) Aerial Census of Elephants and other Large Herbivores in the Sebungwe Region and Gonarezhou National Park, Zimbabwe, 1998. WWF-SARPO Project Paper 71. WWFSARPO, Harare, Zimbabwe.

Mackie, C.S. (2002) Aerial Census of Elephants and other Large Herbivores in the Sebungwe Region, Zimbabwe: 2001. WWFSARPO Occasional Paper 3. WWF-SARPO, Harare, Zimbabwe.

Martin, R.B. (1986) Communal Areas Management Programme for Indigenous Resources (CAMPFIRE). Department of National Parks and Wild Life Management, Harare, Zimbabwe.

Martin, R.B. (1992a) The number of elephants killed in Zimbabwe: 1960-1991. In Elephant Management in Zimbabwe, 2nd edition (eds R.B. Martin, G.C. Craig \& V.R. Booth), pp. 45-49. Department of National Parks and Wild Life Management, Harare, Zimbabwe.

Martin, R.B. (1992b) Maximum likelihood analysis of the elephant population estimates for Matabeleland North, Zimbabwe. In Elephant Management in Zimbabwe, 2nd edition (eds R.B. Martin, G.C. Craig \& V.R. Booth), pp. 87-91. Department of National Parks and Wild Life Management, Harare, Zimbabwe.

Martin, R.B., Craig, G.C. \& Booth, V.R. (eds) (1989) Elephant Management in Zimbabwe. Department of National Parks and Wild Life Management, Harare, Zimbabwe.

Martin, R.B. \& Taylor, R.D. (1983) Wildlife conservation in a regional land-use context: the Sebungwe region of Zimbabwe. In Management of Large Mammals in African Conservation Areas (ed. R.N. Owen-Smith), pp. 249-270. Haum Educational Publishers, Pretoria, South Africa.

Milliken, T., Burn, R.W. \& Sangalakula, L. (2007) The Elephant Trade Information System (ETIS) and the Illicit Trade in Ivory: A report to the 14th meeting of the Conference of the Parties to CITES. CoP14 Doc. 53.2 Annex. CITES Secretariat, Geneva, Switzerland.

Norton-Griffiths, M. (1978) Counting Animals, 2nd edition. African Wildlife Leadership Foundation, Nairobi, Kenya.

Osborn, F.V. (1998) The ecology of crop-raiding elephants in Zimbabwe. D.Phil. thesis, University of Cambridge, Cambridge, UK.

Payne, K. (1998) Silent Thunder. The Hidden Voice of Elephants. Weidenfeld and Nicolson, London, UK.

Price Waterhouse (1996) Elephant Census in Zimbabwe. An Analysis and Review. Price Waterhouse, Harare, Zimbabwe.

Reeve, R., Tuite, C., Gabriel, G., Bell, J. \& Pueschel, P. (2003) The proposed sale of ivory from Botswana, Namibia and South Africa: conditions and verification. Pachyderm, 35, 115-131.

Sokal, R.R. \& Rohlf, F.J. (1981) Biometry, 2nd edition. W.H. Freeman \& Company, San Francisco, USA.

Taylor, R.D., Cumming, D.H.M. \& Mackie, C. (1992) Aerial Census of Elephant and other Large Herbivores in the Sebungwe 1991. WWF-SARPO Project Paper 29. WWF-SARPO, Harare, Zimbabwe.

Taylor, R.D. \& Mackie, C.S. (1993) Aerial Census of Elephant and other Large Herbivores in the Sebungwe and Western Dande 1992. WWF-SARPO Project Paper 37. WWF-SARPO, Harare, Zimbabwe.

Timberlake, J.R., Nobanda, N. \& Mapaure, I. (1993) Vegetation survey of the communal lands - north and west Zimbabwe. Kirkia, 14, 171-270. 
van Aarde, R.J. \& Jackson, T.P. (2007) Megaparks for metapopulations: addressing the causes of locally high elephant numbers in southern Africa. Biological Conservation, 134, 289-297.

Wilkinson, L. (1997) SYSTAT 7.0: New Statistics. SPSS Inc., Chicago, USA.

Appendix A maximum likelihood estimator to compare population estimates, complete with variances, to predicted population numbers (adapted with the permission of Rowan Martin, from Martin, 1992b).

The temporal trend in the number of elephants in a model population can be compared with survey estimates of the real population number using Martin's (1992b) maximum likelihood analysis. For each year during which a population is surveyed the analysis compares the population number predicted by the model to the survey estimate. It does this by relating the difference between the predicted and estimated numbers to the variance of the mean estimate of population number.

For each survey year the number of elephants predicted by a model is compared to the survey estimate (Fig. A1). The bell-shaped curve for the normal distribution is represented by the formula for the normal probability density function (Sokal \& Rohlf, 1981). There are two parameters in this formula, namely the population mean and the population standard deviation. The population mean is assumed to equal the mean (sample) estimate of the number of elephants, as determined by the survey, and the population standard deviation is assumed to equal the square root of the variance of this sample estimate. The values on the curve corresponding to the predicted number of elephants and the estimated number of elephants are determined (Fig. A1), and the first value divided by the second to give Martin's (1992b) 'relative value'. Martin points out that the relative value is not a true probability but a value that equals one if the predicted and estimated numbers are identical, and declines towards zero as the difference between these two numbers increases.

The product of the relative values for all survey years forms a maximum likelihood estimator that equals one if the predicted and estimated numbers are identical during all survey years, and declines towards zero the

\section{Biographical sketch}

Kevin Dunham is an independent wildlife biologist based in Zimbabwe. His interests include the management and conservation of large mammals. Since 1999 he has often been a member of the WWF-SARPO/ PWMA teams that have conducted elephant surveys in Zimbabwe.

less perfect the fit between the predicted and estimated population numbers. For convenience, the product is multiplied by 1,000 to give the 'index value'.

The analysis is performed by running several models (for example, models with different combinations of a starting population number and a population growth rate), and determining which model gives the greatest value for this index value. This is the model that provides the best fit to the survey estimates.

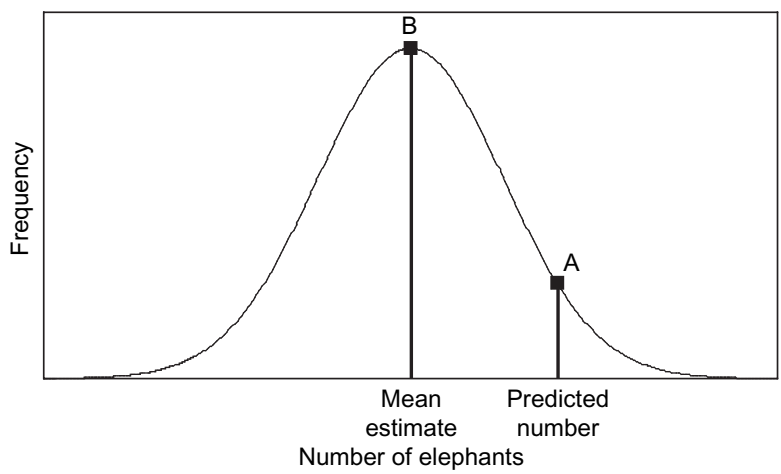

Fig. A1 An illustration of how the number of elephants predicted by a model was compared to that year's survey estimate of elephant number, using Martin's (1992b) 'relative value'. The bellshaped curve for a normal distribution (shown) is represented by the formula for the normal probability density function. In this formula, the population mean is taken to be the mean (sample) estimate of the number of elephants, as determined by the survey; and the population standard deviation is taken to be the square root of the variance of this sample estimate. The vertical lines indicate the values on the curve that correspond to the number of elephants predicted by the model (value A) and the estimated number of elephants (value B). Martin's 'relative value' = A/B. This relative value equals one if the predicted and estimated numbers are identical and declines towards zero as the difference between them increases. 